This is a peer-reviewed, accepted author manuscript of the following paper: Sanjari, M., Hadadzadeh, A., Shahriari, A., Tamimi, S., Pirgazi, H., Amirkhiz, B. S., Kestens, L., \& Mohammadi, M. (2020). On the effect of building direction on the microstructure and grain morphology of a selective laser melted maraging stainless steel. In Z. Peng, J-Y. Hwang, J. Downey, D. Gregurek, B. Zhao, O. Yucel, E. Keskinkilic, T. Jiang, J. White, \& M. Mahmoud (Eds.), TMS 2020 149th Annual Meeting and Exhibition Supplemental Proceedings (pp. 285-295). Springer. https://doi.org/10.1007/978-3-030-36296-6 27

\title{
On the effect of building direction on the microstructure and grain morphology of a selective laser melted maraging stainless steel
}

\author{
Mehdi Sanjari ${ }^{1,2}$, Amir Hadadzadeh ${ }^{1,2}$, Ayda Shahriairi ${ }^{1}$, Saeed Tamimi ${ }^{3}$, Hadi Pirgazi ${ }^{4}$, Babak Shalchi \\ Amirkhiz $^{2,1}$, Leo Kestens ${ }^{4}$, Mohsen Mohammadi ${ }^{1}$ \\ ${ }^{1}$ Marine Additive Manufacturing Centre of Excellence (MAMCE), University of New Brunswick, \\ Fredericton, NB, Canada \\ ${ }^{2}$ CanmetMATERIALS, Natural Resources Canada, 183 Longwood Road South, Hamilton, ON, Canada \\ LSP $0 A 5$ \\ ${ }^{3}$ Advanced Forming Research Centre- AFRC, Manufacture and Engineering Management, University of \\ Strathclyde, Glasgow, UK \\ ${ }^{4}$ Department of Materials Science and Engineering, Ghent University, Ghent, Belgium
}

\begin{abstract}
In this study, cylindrical rods of a low carbon $\mathrm{Fe}-\mathrm{Cr}-\mathrm{Ni}$-Al maraging stainless steel (CX) were fabricated through selective laser melting (SLM) technique for both horizontal direction and cube samples with the dimensions of $15 \times 15 \times 15 \mathrm{~mm}$. The microstructure and grain morphology of the as-built sample were studied using scanning electron microscopy (SEM), electron backscatter diffraction (EBSD), and transmission electron microscopy (TEM). It was observed that in both cases the microstructure of the as-built sample consists of columnar dendrites aligned in the building direction because of the fast-directional cooling presents in the SLM process. However, the microstructural studies revealed that by changing the building method from cube to horizontal, both dendritic and grain structures have a tendency to change. Furthermore, the TEM results showed that different volume fractions of austenite and martensite phases were detected in both directions resulting from complex heat history and wide temperature range during the SLM process.
\end{abstract}

Keywords:

Direct metal laser sintering (DMLS), Additive manufacturing, Electron backscattering diffraction (EBSD), maraging stainless steel (CX)

\section{Introduction}

Additive manufacturing (AM) describes various techniques for building a three-dimensional (3D) geometry in a layer-by-layer fashion [1-2]. A number of metal additive manufacturing (AM) processes are currently available, depending on the heat source [2-4], such as electron beam [5-8], laser, or arc [3, 4, 9, 10], and on how the raw material is supplied. Cooling rates during and after solidification are affected and controlled by the absorbed power (P) and beam velocity (V) combinations and by the geometry of the samples and also any preheating of the substrate [2]. These variables, along with the subsequent heat treatment affect the resulting microstructures [4]. 
In another aspect, it has been always desirable to make products more functional, powerful and reliable materials. Therefore, Stainless steel CX is a newly developed tooling grade steel powder feedstock which has high strength, corrosion resistance and relatively good ductility and have been used for applications in the chemical, aerospace, naval and nuclear industries [11]. This alloy has the same chemical composition of $13.8 \mathrm{Mo}$ PH stainless steel. In other words, the CX stainless steel similar to $13.8 \mathrm{Mo} \mathrm{PH}$ stainless steel is a type of Maraging stainless steels which obtains much of its strength from precipitation reactions [11].

Precipitation hardening $(\mathrm{PH})$ stainless steels are one of the material systems which are being investigated for potential replacements for Ti-6Al-4V. These steels are typically denser than Ti-6Al-4V, but are less expensive, possess superior corrosion resistance and can achieve much higher strengths. If the strength to density ratio is increased enough in these alloys, they could be considered suitable replacements for Ti-6Al-4V. With the improved mechanical properties of these alloys they have become viable replacements for Ti-6Al-4V.

The microstructures for these alloys are typically martensite but can contain small amounts of retained austenite and $\delta$-ferrite in the form of stringers. The precipitates are on the nanometer scale and cannot be viewed light optically [ $11,12]$.

The Complex interaction between the process parameters in laser based PBF AM processes results in different grain orientation and grain sizes. On the other hand, although the effect of building direction on the mechanical properties of AM materials have been reported [13], its role on texture and microstructure evolution has not been studied. Hence, the purpose of this study is to analyze the effect of building direction on the microstructure and texture during DMLS of Corrax alloy.

\section{Experimental procedure}

The gas-atomized powder of stainless steel CX (SS CX) with the nominal chemical composition shown in Table 1 was used in this study. The most of the powder particles are spherical shaped with a mean particle size of approximately $37.5 \mu \mathrm{m}$.

Table 1. Nominal chemical composition of the SS CX. (wt.\%)

\begin{tabular}{|l|l|l|l|l|l|l|l|}
\hline Element & $\mathrm{C}$ & $\mathrm{Mn}$ & $\mathrm{Si}$ & $\mathrm{Cr}$ & $\mathrm{Ni}$ & $\mathrm{Mo}$ & $\mathrm{Al}$ \\
\hline $\mathrm{CX}$ & 0.05 & 0.40 & 0.40 & $11-13$ & $8.4-10$ & $1.1-1.7$ & $1.2-2$ \\
\hline
\end{tabular}

An EOS M290 machine located at Additive Metal Manufacturing Company in Concord, ON, Canada, was employed to fabricate the cube samples and horizontal rod sample.

The laser power, scanning speed, hatching distance, and powder layer thickness values are the same as the ones used for virgin powder and it yields the least porosity and the best mechanical properties, where they are listed in Table 3 . The samples were manufactured under $\mathrm{Ar}-0.1 \% \mathrm{O} 2$ atmosphere using the strip scanning strategy where the laser beam was rotated 67 degrees between consecutive layers.

Table 2. SLM process parameters used in this study.

\begin{tabular}{|c|c|c|c|c|}
\hline Laser type & Laser power $(\mathrm{W})$ & Scanning speed $(\mathrm{mm} / \mathrm{s})$ & Hatching distance $(\mu \mathrm{m})$ & Layer thickness $(\mu \mathrm{m})$ \\
\hline Yb-Fiber & 258.7 & 1066.7 & 100 & 30 \\
\hline
\end{tabular}

To investigate the impact of building direction on the microstructure evolution and mechanical properties rod shaped samples with $120 \mathrm{~mm}$ height and $12 \mathrm{~mm}$ diameter were manufactured in horizontal direction. The longitudinal axes in the vertical and horizontal samples were parallel and perpendicular to the building direction, respectively. 
Microstructural analyses were performed perpendicular to the longitudinal axes of the rods. Therefore, the microstructure of the horizontal sample was studied in the $y-z$ plane, where for the vertical sample the microstructure was analyzed in the $\mathrm{x}-\mathrm{y}$ plane.

\section{Results \& discussion}

\subsection{Grain structure}

EBSD inverse pole figure (IPF-Z) and grain boundary maps of the vertical and cube samples from side view are shown in Fig. 1. Since the crystallographic texture along the building direction (z) was of interest, the z-direction coloring map was used in the EBSD-IPF images.
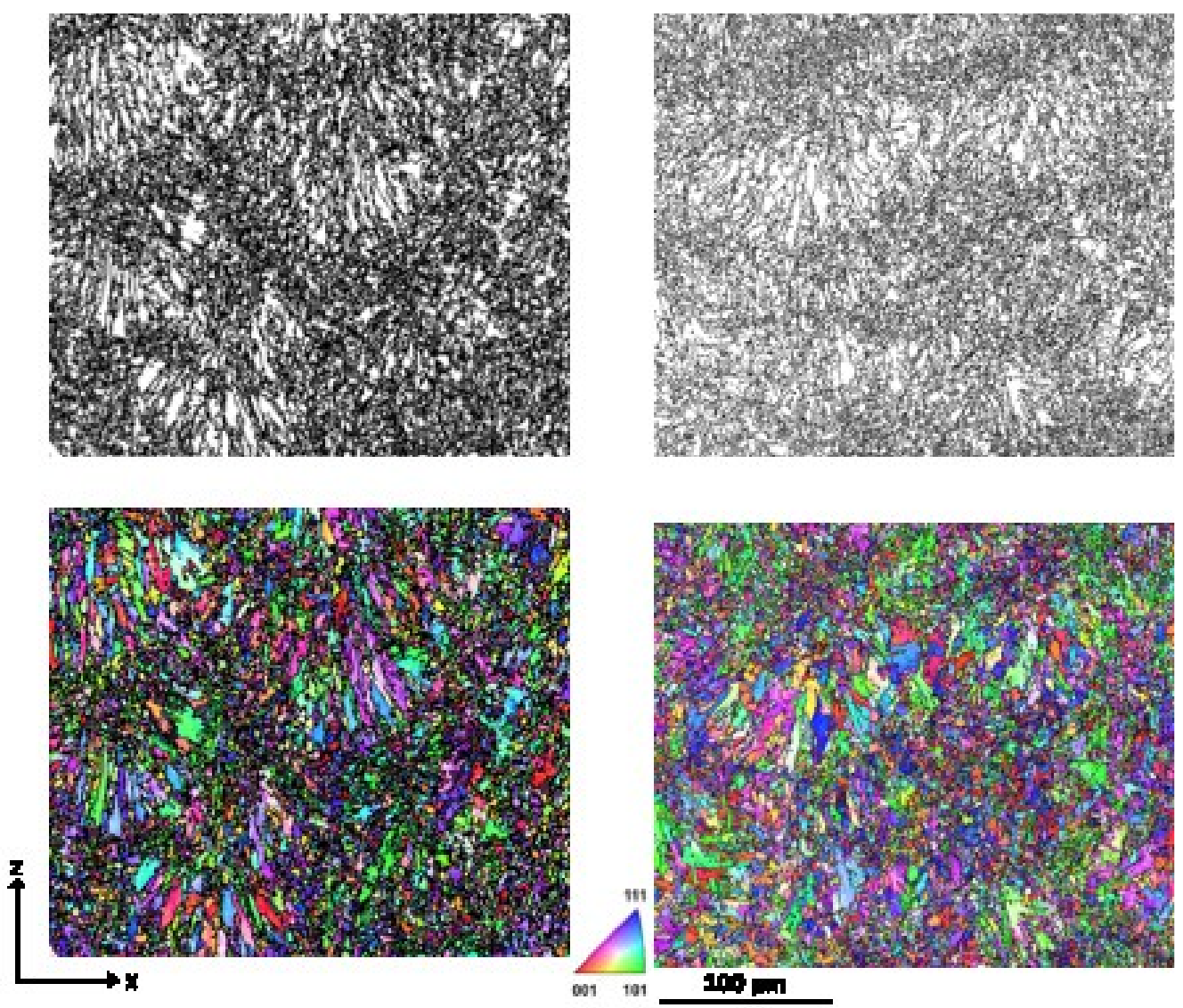

(a)

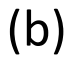

Fig. 1. EBSD IPF-Z and grain boundary maps of (a) cube and (b) horizontal samples superimposed with grain boundaries.

Fig. 2 shows the effects of building method on the grain size and the fraction of columnar and equiaxed grains in DMLS-Corrax alloy built in both horizontal directions and cube configuration.

As it can be seen from Fig 1 and 2, by changing the building method from cube to horizontal, the grain morphology have not been changed that much but slightly shifted from equiaxed to columnar from cube to horizontal sampl. The cube samples also have slightly larger garin size which can be seen in Fig 2 (a). As it shows in Fig 1, in both cases the majority of grains are large columnar ones oriented along the building direction (z). However, similar to other DMLS alloys, the boundary of melt pools in both samples, consisted of equiaxed grains $[14,15]$. Nevertheless, the 
grains in the horizontally built sample are not perfectly parallel to the building direction, but tilted some degrees from the z-axis.

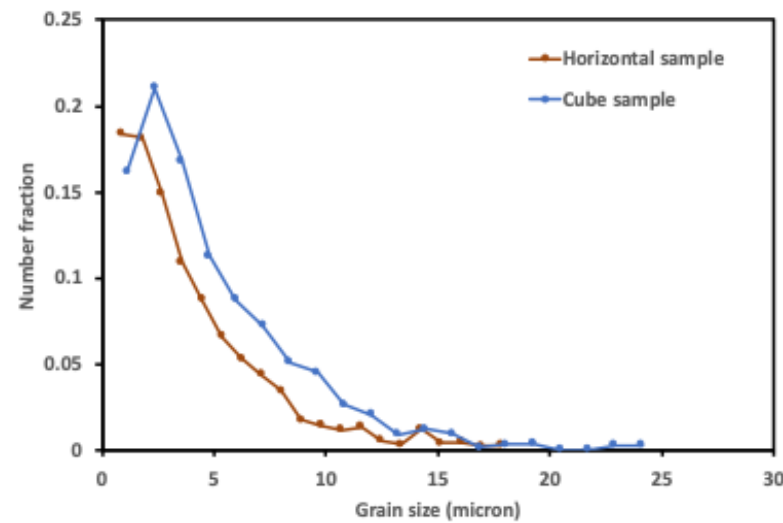

(a)

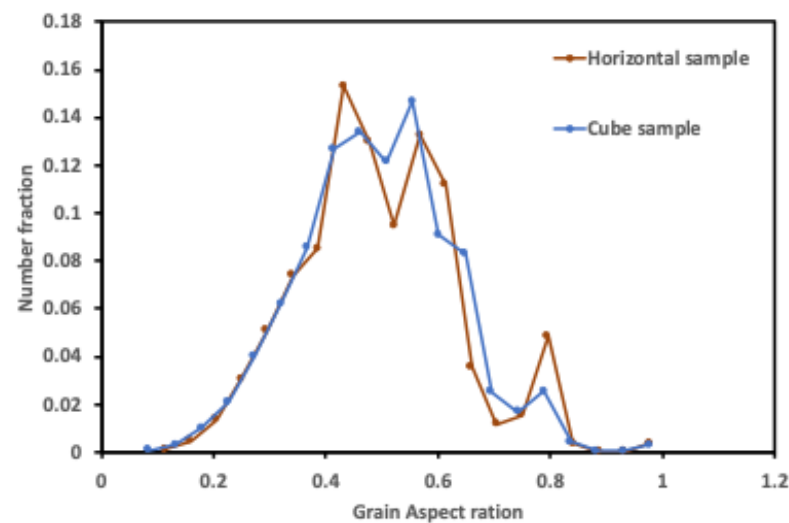

(b)

Fig. 2. Effect of building method on grains (a) grain size, (b) fraction of columnar and equiaxed grains.

To investigate the effect of building direction on grain shape, the fraction of columnar and equiaxed grains was evaluated in each sample from the IPF maps and presented in Fig. 2 (b). The criterion to identify columnar and equiaxed grains was the grain shape aspect ratio $(\phi)$. To evaluate the grain shape aspect ratio, an ellipse was fitted to each grain and major axis (L1) and minor axis (L2) of each ellipse was evaluated, where the grain shape aspect ratio was defined as $\phi=\mathrm{L} 2 / \mathrm{L} 1$. Columnar grains were determined with $\phi \leq 0.33$ (L2: L1 $\equiv 1: 3$ and lower), while equiaxed grains possessed $\phi>0.33$. Referring to Fig. 2 (b), it is noted that, despite the difference in grain size, the grain aspect ratio in two samples, was not altered significantly due to changing the building method.
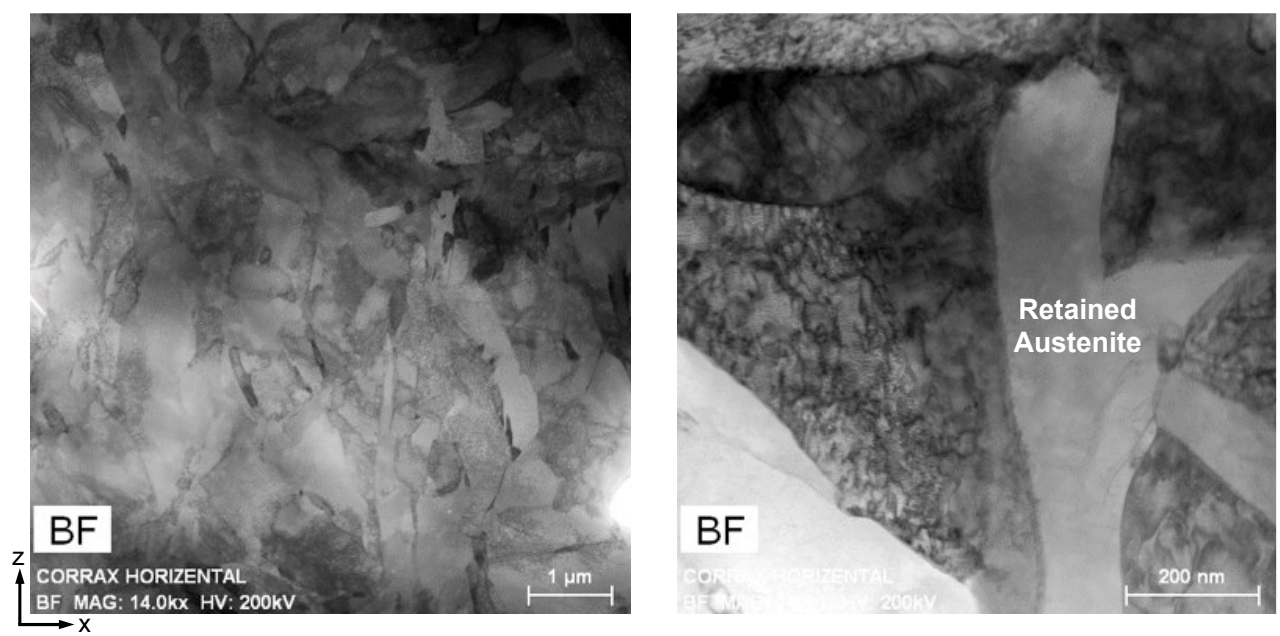

Figure 3. STEM-BF micrographs of SLM-SS CX on the side plane of horizontal sample (a) inside the melt pool, (b) higher magnification of the enclosed area.

Figure 3 illustrates the STEM bright field (STEM-BF) micrographs of the horizontal sample. As can be seen, there are packets of martensite which shows the morphology and internal structure of the laths. The lath boundaries could be considered as small angle boundaries. It is noted that very high density of dislocations is formed in the martensite 
laths which might be due to phase transformation from the austenite to martensite which create dislocations by the advancing austenite-martensite boundaries and therefore resulted in the post-transformation stresses.

\subsection{Texture evolution}

To study the effect of process parameters on the texture evolution, Fig. 4 shows the $\phi 2=0$ and $45^{\circ}$ sections of Orientation Distribution Function (ODF) of cube and horizontal samples obtained from two corresponding large EBSD scans size of around $450 \times 850 \mu \mathrm{m}^{2}$.

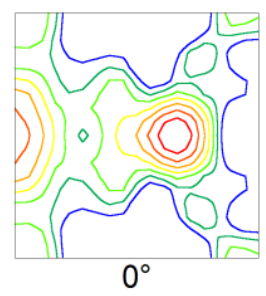

(a)

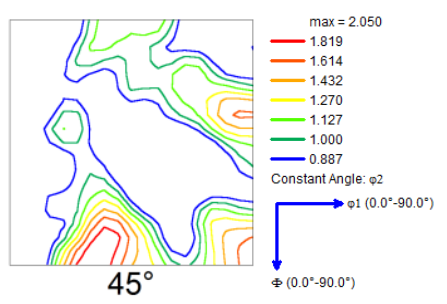

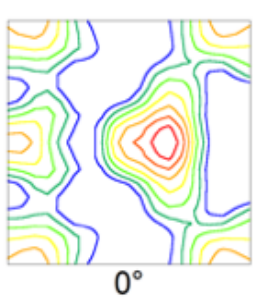

(b)

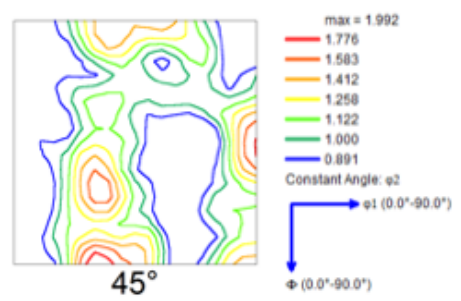

Fig. 4. $\phi_{2}=0$ and $45^{\circ}$ sections of Orientation Distribution Function (ODF) of (a) cube and (b) horizontal samples obtained from a large EBSD scans size of $450 \times 850 \mu \mathrm{m}^{2}$

As can be seen in Fig 4, development of a columnar grain structure in both samples led to the presence of some components such as cube components in both samples which is more evident in horizontal sample. An $\{111\}<112>$ component can be found in horizontal sample which is absent in cube samples. In both cases, Goss $(\{110\}<001>)$ and Copper $((\{112\}<111>)$ presented in both cases.

\subsection{Grain orientation spread}

The microstructure of parts fabricated by SLM process can vary significantly from those of conventional methods such as wrought or casting processes. The locally high cooling rates, as well as non-equilibrium solidification conditions, are main factors to create materials contain substantial solute segregation with the formation of terminal solidification phases and also grains with in-grain mis-orientation [16, 17]. Consequently, SLM components with varied microstructures may exhibit different properties in comparison with their conventional wrought or cast counterparts and need subsequent heat treatment such as stress relief and annealing [18].

One important parameter that can strongly affect the subsequent annealing and stress relief process is local variations in misorientations which is an indicator of strain in crystalline materials. To investigate this in the printed samples, in this work, the grain orientation spread (GOS) in deg $\left(^{\circ}\right)$ has been used for this purpose.

According to Allain-Bonasso et al. [19], GOS of grain i is calculated as follows:

$$
\operatorname{GOS}(\mathrm{i})=\frac{1}{J(i)} \sum_{j} W_{i j}
$$

where $J(i)$ is the number of scan points in grain $i$, Wij is the mis-orientation angle between the orientation of scan point $j$ and the mean orientation of grain $i$. Because of high cooling rate during AM process some grains has a higher GOS value than the others. In this work, the threshold value for GOS to separate the relaxed grains from the un-relaxed ones set as $1 \operatorname{deg}\left({ }^{\circ}\right)$. The results can bee seen for both cube and horizontal samples in Fig. 5. 


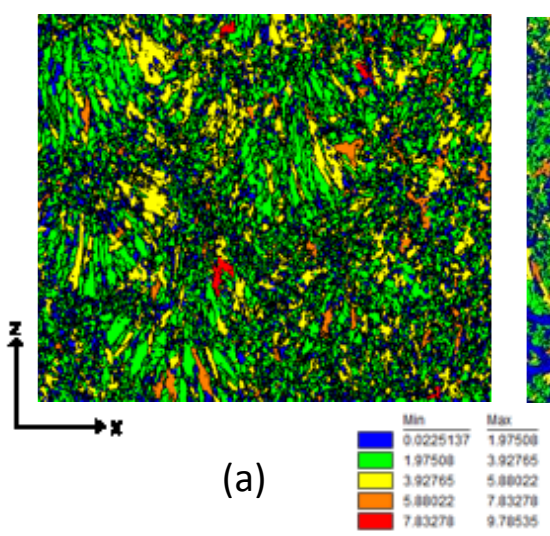

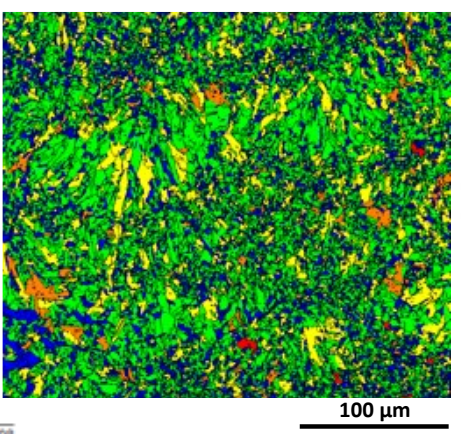

(b)

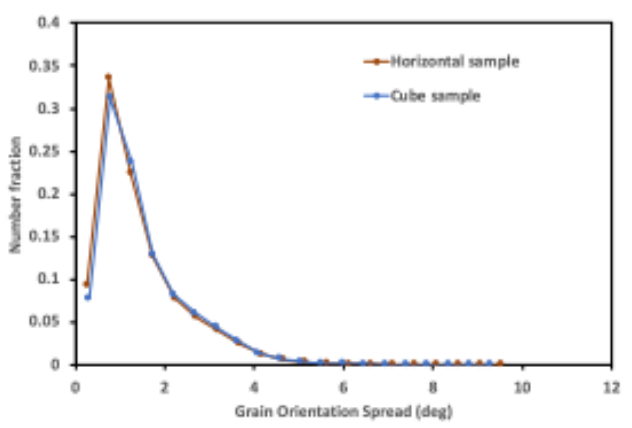

(c)

Fig. 5. Grain orientation spread (GOS) at (a) cube and (b) horizontal samples. (c) GOS and corresponding number fraction for both cube and horizontal sample.

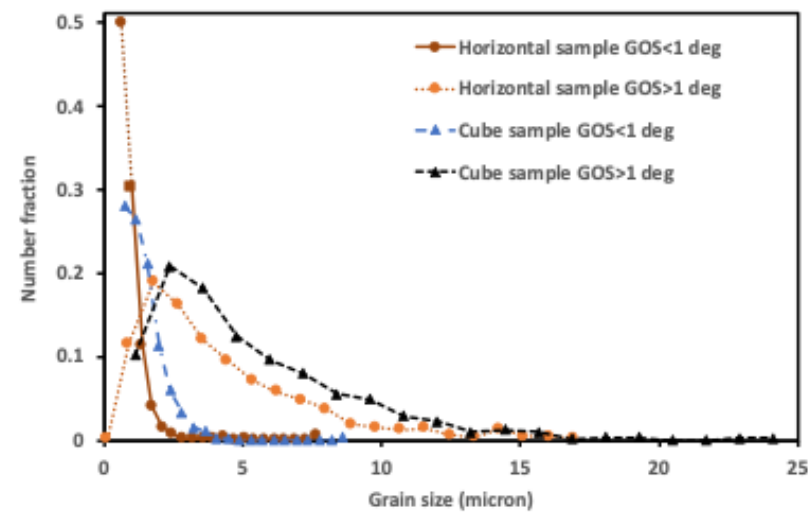

(a)

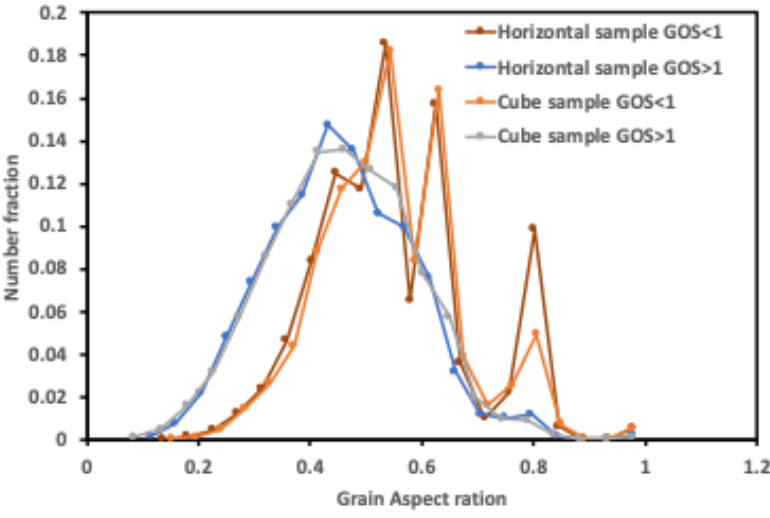

(b)

Fig. 6 (a) Grain size and (b) grain aspect ratio separated based on the GOS in both Cube and horizontal samples.

To investigate the relationship between the GOS and grain size or grain aspect ratio, the maps were partitioned based on GOS criteria of $1 \mathrm{deg}$. The results has been shown in Fig 6 . As can be seen The grains with GOS $<1$ are much smaller in size compare with the grains with GOS $>1$ in both samples. However, there is no meaningful difference can be found in terms of grain aspect ratio. 


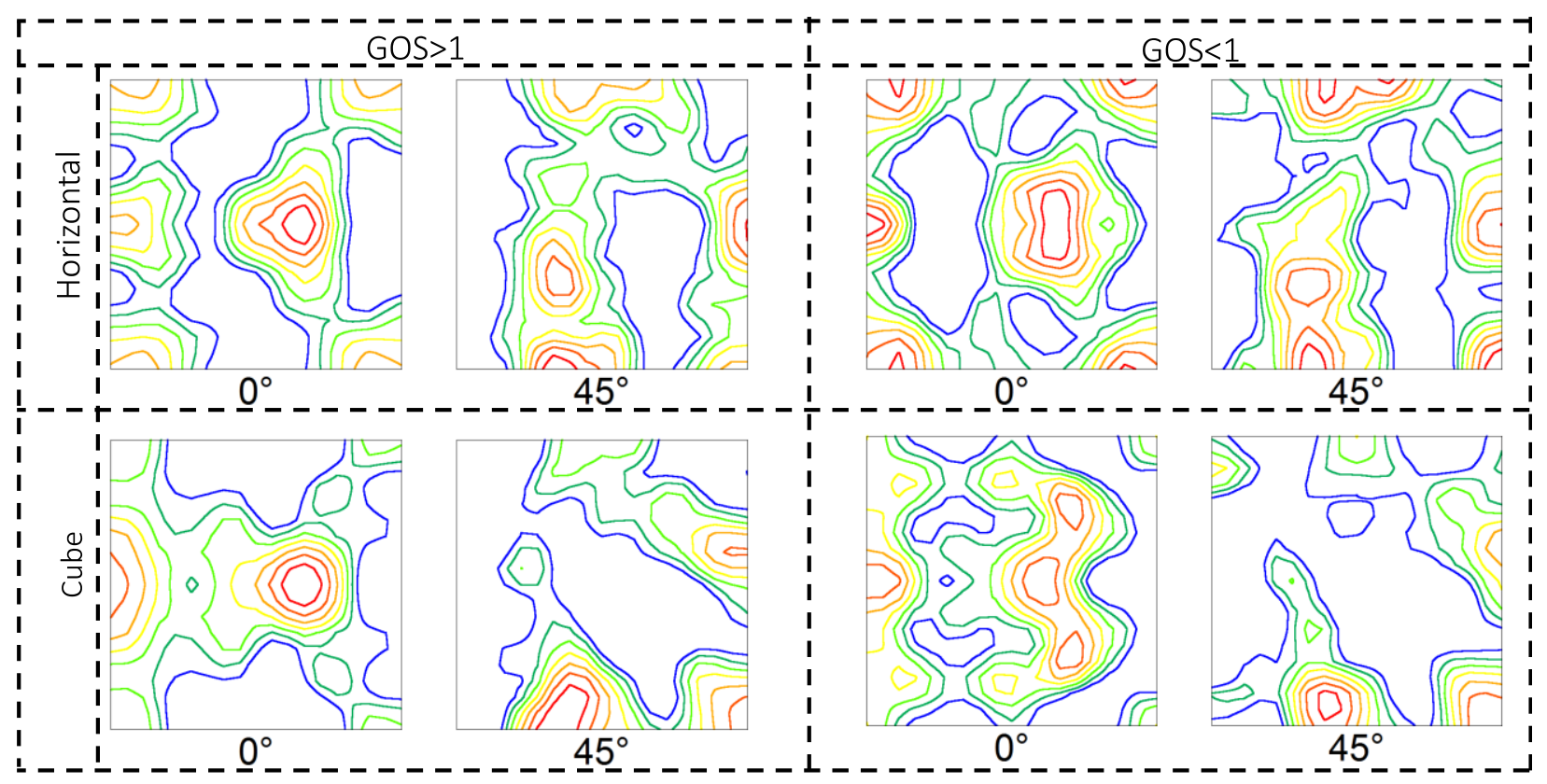

Fig. $7 \phi_{2}=0$ and $45^{\circ}$ sections of the orientation distribution function (ODF) separated based on the GOS in both Cube and horizontal samples.

Figure 6 is illustrated the $\phi_{2}=0$ and $45^{\circ}$ sections of the orientation distribution function (ODF) calculated based on the GOS in both Cube and horizontal samples. As can be seen the textures does not differ significantly for the both samples. In cube samples, some components on GOS $<1$ and $\phi_{2}=0$ can be observed which is very different from GOS $>1$.

\section{Conclusions}

In the current study, the effect of building direction on texture and grain structure of Corrax during DMLS process was studied. A cube and a horizontal cylindrical sample were printed using the same process parameters. Using different characterization technique the microstructure of the samples along with their grain shape and orientation characteristics were studied

It was observed that in both cases the microstructure of the as-built sample consists of columnar dendrites aligned in the building direction because of the fast-directional cooling presents in the SLM process. However, the microstructural studies revealed that by changing the building method from cube to horizontal, both dendritic and grain structures have a tendency to change.

\section{References}

[1] D.D. Gu, W. Meiners, K. Wissenbach, R. Poprawe, Laser additive manufacturing of metallic components: materials, processes and mechanisms, Int. Mater. Rev. 57 (2012) 133-164, https://doi.org/10.1179/1743280411Y.0000000014.

[2] John J. Lewandowski and Mohsen Seifi, Metal Additive Manufacturing: A Review of Mechanical Properties, Annu. Rev. Mater. Res. 2016. 46:151-86

[3] FrazierWE. 2014. Metal additive manufacturing: a review. J. Mater. Eng. Perform. 23(6):1917-28

[4] Dutta B, Froes FHS. 2014. Additive manufacturing of titanium alloys. Adv. Mater. Res. 1019(Oct.):19-25 
[5] Facchini L, Magalini E, Robotti P, Molinari A. 2009. Microstructure and mechanical properties of Ti-6Al-4V produced by electron beam melting of pre-alloyed powders. Rapid Prototyp. J. 15(3):171-78

[6] Parthasarathy J, Starly B, Raman S, Christensen A. 2010. Mechanical evaluation of porous titanium (Ti6Al4V) structures with electron beam melting (EBM). J. Mech. Behav. Biomed. Mater. 3(3):249-59

[7] Murr LE, Gaytan SM, Ramirez DA, Martinez E, Hernandez J, et al. 2012. Metal fabrication by additive manufacturing using laser and electron beam melting technologies. J. Mater. Sci. Technol. 28(1):1-14

[8] Collins PC, Haden CV, Ghamarian I, Hayes BJ, Ales T, et al. 2014. Progress toward an integration of processstructure-property -performance models for 'three-dimensional (3-D) printing' of titanium alloys. JOM 66(7):1299309

[9] Yu J, Rombouts M, Maes G, Motmans F. 2012. Material properties of Ti6Al4V parts produced by laser metal deposition. Phys. Procedia 39:416-24

[10] Leuders S, Th"one M, Riemer A, Niendorf T, Tr" oster T, et al. 2013. On the mechanical behaviour of titanium alloy TiAl6V4 manufactured by selective laser melting: fatigue resistance and crack growth performance. Int. J. Fatigue 48:300-7

[11] H Asgari, M Mohammadi, Microstructure and mechanical properties of stainless steel CX manufactured by Direct Metal Laser Sintering, Materials Science \& Engineering A 709, 82-89

[12] Hamlin, R.J. and J.N. DuPont, Microstructural Evolution and Mechanical Properties of Simulated HeatAffected Zones in Cast Precipitation-Hardened Stainless Steels 17-4 and 13-8+ Mo. Metallurgical and Materials Transactions A, 2017. 48(1): p. 246-264.

[13] [25] H. Rao, S. Giet, K. Yang, X. Wu, C.H.J. Davies, The influence of processing parameters on aluminium alloy A357 manufactured by Selective Laser Melting, Mater. Des. 109 (2016) 334-346,

https://doi.org/10.1016/j.matdes.2016.07.009.

[14] K.V. Yang, Y. Shi, F. Palm, X. Wu, P. Rometsch, Columnar to equiaxed transition in Al-Mg(-Sc)-Zr alloys produced by selective laser melting, Scr. Mater. 145 (2018) 113-117, https://doi.org/10.1016/j.scriptamat.2017.10.021.

[15] N. Takata, H. Kodaira, K. Sekizawa, A. Suzuki, M. Kobashi, Change in microstructure of selectively laser melted AlSi10Mg alloy with heat treatments, Mater. Sci. Eng. A 704 (2017) 218-228, https://doi.org/10.1016/j.msea.2017.08.029.

[16] Thijs, L., et al., A study of the microstructural evolution during selective laser melting of Ti-6Al-4V. Acta materialia, 2010. 58(9): p. 3303-3312.

[17] Raza, M.R., et al., Effects of cooling rate on mechanical properties and corrosion resistance of vacuum sintered powder injection molded 316L stainless steel. Journal of Materials Processing Technology, 2012. 212(1): p. 164170.

[18] Schaller, R.F., et al., Corrosion properties of powder bed fusion additively manufactured 17-4 PH stainless steel. Corrosion, 2017. 73(7): p. 796-807.

[19] N. Allain-Bonasso, F. Wagner, S. Berbenni, D.P. Field A study of the heterogeneity of plastic deformation in IF steel by EBSD Mater. Sci. Eng. A, 548 (2012), pp. 56-63 